\title{
Penggunaan Media Sosial Dalam Penyuluhan Pertanian Di Kecamatan Tiumang Kabupaten Dharmasraya
}

\author{
${ }^{1}$ Eza Safitri, ${ }^{2}$ Ernita Arif, Asmawi \\ ${ }^{123}$ Program Studi Ilmu Penyuluhan dan Komunikasi Pembangunan, \\ Universitas Andalas, Indonesia \\ e-mail: syavinaalyzaputri@gmail.com
}

\begin{abstract}
Abstrak
Fenomena penggunaan media sosial di masyarakat diharapkan bisa meningkatkan layanan informasi dan mempermudah kegiatan penyuluhan. Penyuluh dan petani diharapkan bisa bertukar informasi dengan penyuluh yang ada di daerah lain dengan mudah, cepat, dan murah. Sebagian besar penyuluh di Kabupaten Dharmasraya menggunakan media sosial sebagai media penyuluhan dalam melakukan kegiatan penyuluhan pertanian. Media sosial merupakan salah satu media penyuluhan yang digunakan oleh para penyuluh dalam memberikan berbagai informasi kepada para petani. Penelitian ini bertujuan untuk menganalisis penggunaan media sosial oleh penyuluh dalam aktivitas penyuluhan di Kecamatan Tiumang Kabupaten Dharmasraya, mengalisis hambatan-hambatan penggunaan media sosial oleh penyuluh dalam aktivitas penyuluhan di Kecamatan Tiumang Kabupaten Dharmasraya, dan menganalisis dampak penggunaan media social dalam aktivitas penyuluhan di Kecamatan Tiumang Kabupaten Dharmasraya. Metode penelitian ini menggukan pendekatan kualitatif. Jenis data terdiri atas data primer dan sekunder yang kemudian dianalisa menggunakan teknis Miles and Huberman yang terdiri atas data reduction, data display, dan conclusion drawing/ verification. Hasil penelitian menunjukkan bahwa penggunaan media sosial dalam aktivitas penyuluhan di lokasi penelitian sudah baik, di mana media sosial dimanfaatkan untuk aktivitas penyuluhan, pelatihan, dan sosialisasi. Selain itu media sosial juga digunakan untuk diskusi dengan penyuluh atau sesama petani terkait pertanian, mencari lebih banyak informasi mengenai pertanian, dan memasarkan hasil pertanian melalui berbagai aplikasi media sosial. Dampak positif penggunaan media sosial adalah peningkatan akurasi, efisiensi, dan efektifitas penyuluhan, menjadi media pembelajaran dan sharing informasi, serta peningkatan produktivitas pertanian
\end{abstract}

Keywords: media sosial, penyuluhan, penyuluh, petani.

\begin{abstract}
The phenomenon of the use of social media in the community is expected to improve information services and facilitate counseling activities. Extension agents and farmers are expected to exchange information with extension agents in other regions easily, quickly, and cheaply. Most of the extension workers in Dharmasraya Regency use social media as a media extension in conducting agricultural extension activities. Social media is one of the extension media used by extension agents in providing various information to farmers. This study aims to analyze the use of social media by extension agents in extension activities in Tiumang Subdistrict, Dharmasraya District, analyze barriers to the use of social media by extension agents in extension activities in Tiumang District, Dharmasraya District, and analyze the impact of using social media in extension activities in Tiumang District Dharmasraya. This research method uses a qualitative approach. The type of data consists of primary and secondary data which is then analyzed using the technical Miles and Huberman consisting of data reduction, data display, and conclusion drawing / verification. The results showed that the use of social media in extension activities
\end{abstract}


at the research location was good, where social media was used for extension activities, training, and outreach. Besides that social media is also used for discussions with extension agents or fellow farmers related to agriculture, looking for more information about agriculture, and marketing agricultural products through various social media applications. Barriers to the use of social media at the study site are limited facilities so that the internet network is often unstable, especially when power outages and bad weather. The positive impact of using social media is increasing the accuracy, efficiency and effectiveness of counseling, becoming a medium for learning and sharing information, and increasing agricultural productivity. Therefore, in this study it is recommended to improve the facilities and infrastructure to support the internet network in the study location so that the use of social media in agricultural extension is more optimal to achieve the welfare of farmers..

Kata Kunci : counseling, extension, farmers, social media

\section{PENDAHULUAN}

Sementara itu Samsudin (1982) memberikan pengertian penyuluhan pertanian sebagai suatu cara atau usaha pendidikan yang bersifat non formal untuk para petani dan keluarganya di pedesaan. Penyuluhan pertanian mengandung arti aktivitas pendidikan diluar bangku sekolah (non- formal) yang memiliki sifat- sifat sebagai berikut :

1. Selalu berhubungan dengan masyarakat petani di pedesaan yang sesuai dengan kepentingan atau kebutuhan pada waktu tertentu.

2. Menggunakan cara- cara dan metode pendidikan khusus yang disesuaikan dengan sifat, perilaku dan kepentingan petaninya.

3. Keberhasilan pelaksanaannya memerlukan bantuan berbagai aktivitas baik yang langsung menunjang pendidikan itu maupun yang tidak langsung.

4. Pelaksanaan pendidikan non- formal ini dilangsungkan dalam suasana koperasi dan toleransi, musyawarah untuk memecahkan masalah yang berkaitan dengan pelaksanaan usaha tani.

5. Penyuluhan pertanian atau peternakan merupakan pendidikan non- formal yang ditujukan kepada petani atau peternak beserta keluarganya yang hidup di pedesaan dengan membawa dua tujuan utama yang diharapkan.

Kemajuan teknologi pertanian saat ini semakin pesat, baik teknologi produksi maupun teknologi sosial ekonomi. Persaingan dalam berusaha di bidang pertanian pun semakin meningkat. Tuntutan untuk meningkatkan kualitas produksi tidak dapat ditawar-tawar lagi. Teknologi dan informasi yang berkaitan dengan hal-hal tesebut perlu disalurkan dengan cepat dari sumber pesan kepada sasaran, yakni petani dan keluarganya serta masyarakat pertanian lainnya. Oleh karena itu peranan media sosial didalam penyuluhan pertanian semakin penting.

Pengguna facebook di Indonesia bervariasi mulai dari anak-anak, remaja, hingga manula. Semua kalangan umur di Indonesia terhitung sudah semuanya menggunakan facebook sebagai media komunikasi. 
Tabel 1 Data pengguna facebook 2015

\begin{tabular}{cc}
\hline Umur (Tahun) & Jumlah Akun (Juta) \\
\hline $13-19$ & 26 \\
$20-29$ & 35 \\
$30-39$ & 12 \\
$40-49$ & 3,8 \\
$50-59$ & 1 \\
$\geq 60$ & 1,5 \\
\hline Total & 79 \\
\hline
\end{tabular}

Sumber : Noviandari, 2015 dalam Kadhung Prayoga (2017)

Berdasarkan hasil survey pendahuluan menunjukkan bahwa sebagian besar penyuluh di Kabupaten Dharmasraya menggunakan media sosial sebagai media penyuluhan dalam melakukan kegiatan penyuluhan pertanian. Media sosial merupakan salah satu media penyuluhan yang digunakan oleh para penyuluh dalam memberikan berbagai informasi kepada para petani. Namun, dalam penggunaannya tentu mengalami keterbatasan, seperti kurangnya signal yang kurang mendukung dalam wilayah binaan, faktor usia para petani, sehingga mereka akan sulit mengoperasikan gadget.

Pada wilayah binaan penyuluh itu sendiri, ketersediaan akses media sosial ataupun terbatasnya sarana dan prasarana yang tersedia di Kantor mereka (BPP) masih belum lengkap. Juga terdapatnya beberapa wilayah binaan yang masih kurang akses internetnya, sehingga penyuluh masih belum maksimal dalam memanfaatkan media sosial. Sehingga keterbatasan ini akan mempengaruhi kegiatan penyuluhan di lapangan.

Tujuan penelitian in adalah (1) menganalisis penggunaan media sosial oleh penyuluh dalam aktivitas penyuluhan di Kecamatan Tiumang Kabupaten Dharmasraya. (2) mengalisis hambatanhambatan penggunaan media sosial oleh penyuluh dalam aktivitas penyuluhan di Kecamatan Tiumang Kabupaten Dharmasraya. (3) Menganalisis dampak penggunaan media social dalam aktivitas penyuluhan di Kecamatan Tiumang Kabupaten Dharmasraya.

\section{METODE}

Metode yang digunakan dalam penelitian ini adalah metode kualitatif. Penelitian kualitatif adalah penelitian yang melakukan analisis dan interpretasi teks dan hasil interview dengan tujuan untuk menemukan makna dari suatu fenomena. Menurut Sugiyono (2017: 03) penelitian kualitatif berkenaan dengan data yang bukan angka, mengumpulkan dan menganalisis data yang bersifat naratif. Metode penelitian kualitatif terutama digunakan untuk memperoleh data yang kaya, informasi yang mendalam tentang isu atau masalah yang akan dipecahkan. Metode penelitian kualitatif menggunakan focus group, interview secara mendalam, observasi berperan serta, dalam mengumpulkan data.

Sugiyono (2017: 12) kegunaan dari metode penelitian ini adalah: 1). Menemukan masalah dan potensi 2). Memahami makna dan keunikan objek yang diteliti 3). Memahami proses dan atau interaksi sosial 4). Memahami perasaan orang 5). Mengkonstruksi pemahaman, dan menemukan hipotesis 6). Memastikan kebenaran data 7). Meneliti sejarah perkembangan.

Teknik pengambilan narasumber pada penelitian ini dilakukan dengan menggunakan penentuan informan dan dilakukan secara purposive, yaitu dipilih dengan pertimbangan dan tujuan tertentu. Menurut (Sugiyono, 2017: 94) bahwa peneliti memasuki situasi sosial tertentu, melakukan observasi dan wawancara kepada orang- orang yang dipandang tahu tentang situasi sosial tertentu. 
Situasi sosial terdiri dari tiga elemen yaitu tempat, pelaku, dan aktivitas yang berinteraksi secara sinergis. Situasi tersebut, dapat dinyatakan sebagai objek penelitian yang ingin diketahui "apa yang terjadi" didalamnya. Situasi sosial dalam penelitian ini adalah beberapa orang penyuluh yang ada di Kabupaten Dharmasraya.

Menurut Sugiyono (2017: 131) analisis data adalah proses mencari dan menyusun secara sistematis data yang dipeoleh dari hasil wawancara, catatan lapangan, dan dokumentasi, dengan cara mengorganisasikan data ke dalam kategori, menjabarkan ke dalam unit-unit, melakukan sintesa, menyusun ke dalam pola, memilih mana yang penting dan yang akan dipelajari, dan membuat kesimpulan sehingga mudah difahami oleh diri sendiri maupun orang lain. Analisis data kualitatif bersifat induktif, yaitu suatu analisis berdasarkan data yang diperoleh, selanjutnya dikembangkan menjadi hipotesis.

Analisis data dalam penelitian kualitatif dilakukan sejak sebelum memasuki lapangan, selama dilapangan, dan setelah selesai di lapangan. Dalam hal ini Nasution (1988) dalam Sugiyono (2017:131) menyatakan bahwa analisis telah mulai sejak merumuskan dan menjelaskan masalah, sebelum terjun ke lapangan, dan berlangsung terus sampai penulisan hasil penelitian.

Miles dan Huberman (1984) dalam Sugiyono (2017: 132), mengemukakan bahwa aktivitas dalam analisis data kualitatif dilakukan secara interaktif dan berlangsung secara terus menerus sampai tuntas, sehingga datanya sudah jenuh. Aktivitas dalam analisis data, yaitu data reduction, data display, dan conclusion drawing/verification.

\section{HASIL DAN PEMBAHASAN}

\subsection{Penggunaan Media Sosial dalam Penyuluhan Pertanian}

Kecamatan Tiumang Kabupaten Dharmasraya merupakan salah satu daerah yang menggunakan media sosial sebagai sarana atau media penyebaran informasi dalam aktivitas penyuluhan pertanian. Beragamnya jenis media sosial seperti whatsapp, facebook, instagram, youtube, dan twitter memungkinkan penggunaan media sosial sebagai media belajar dan sumber informasi pertanian (Humaidi et al., 2020). 
Tabel 1 Keterjangkauan sumber informasi penyuluh di Kecamatan Tiumang Kabupaten Dharmasraya.

\begin{tabular}{lll}
\hline \multicolumn{1}{c}{ Aspek keterjangkauan } & \multicolumn{1}{c}{ Keterangan } \\
\hline $\begin{array}{l}\text { 1. Media informasi yang dibutuhkan } \\
\text { dalam mengembangkan penyuluhan }\end{array}$ & & Petunjuk teknis, leaflet/folder, poster, buletin, \\
buku, jurnal, internet.
\end{tabular}

Sumber: hasil olah data primer (2020)

Tabel 2 Keterjangkauan daerah kerja penyuluh di Kecamatan Tiumang Kabupaten Dharmasraya

\section{Aspek keterjangkauan}

Penyuluh Kecamatan Tiumang

Frekuensi (orang) Persentase (\%)

1. Frekuensi kehadiran ke BPP
a. 1 kali sebulan
0
b. 1 kali seminggu
40,00
c. Dua kali seminggu, setiap hari

2. Jarak dari rumah ke BPP
a. $1-5 \mathrm{~km}$
20.00
b. $6-10 \mathrm{~km}$
0.00
c. $>10 \mathrm{~km}$

3. Jarak dari BPP ke wilayah binaan
a. $5-10 \mathrm{~km}$
40.00
b. $11-15 \mathrm{~km}$
40.00
c. $>15 \mathrm{~km}$

4. Jarak dari rumah ke wilayah binaan
a. $1-10 \mathrm{~km}$
b. $11-20 \mathrm{~km}$
40.00
c. $>20 \mathrm{~km}$ 
Aspek keterjangkauan

Penyuluh Kecamatan Tiumang

Frekuensi (orang) Persentase (\%)

5. Frekuensi kunjungan ke wilayah binaan
a. 1 kali sebulan
0
0,00
b. 1 kali seminggu
$0 \quad 0,00$
c. Dua kali seminggu, setiap hari
5
100,00

6. Sarana ke BPP dan lokasi binaan

a. Jalan kaki atau kendaraan umum

$0 \quad 0,00$

b. Kendaraan pribadi (mobil atau motor) $\quad 0 \quad 0,00$

c. Kendaraan dinas (mobil atau motor)

$5 \quad 100,00$

Jumlah

Sumber: hasil olah data primer (2020)

Tabel 3 Sebaran penggunaan media sosial antara penyuluh dan petani di Kecamatan Tiumang Kabupaten Dharmasraya.

\begin{tabular}{|c|c|c|c|}
\hline \multirow{2}{*}{\multicolumn{2}{|c|}{ Aspek sebaran }} & \multicolumn{2}{|r|}{ Keterangan } \\
\hline & & Penyuluh & Petani \\
\hline 1. & $\begin{array}{l}\text { Jenis media yang } \\
\text { digunakan }\end{array}$ & Smartphone android & Smartphone android \\
\hline & $\begin{array}{l}\text { Tahun penggunaan } \\
\text { media / media sosial }\end{array}$ & 2013 & 2018 \\
\hline 3. & $\begin{array}{l}\text { Tahun penggunaan } \\
\text { media sosial sebagai } \\
\text { media penyuluhan }\end{array}$ & 2018 & 2018 \\
\hline 4. & $\begin{array}{l}\text { Jenis media sosial } \\
\text { yang digunakan }\end{array}$ & $\begin{array}{l}\text { - Whatsapp } \\
\text { - Facebook } \\
\text { - Instagram, } \\
\text { - Youtube } \\
\text { - Google }\end{array}$ & $\begin{array}{l}\text { - Whatsapp } \\
\text { - Facebook } \\
\text { - Tokopedia, } \\
\text { - Aplikasi marketplace, } \\
\text { - Aplikasi Prakerja dampak Covid }\end{array}$ \\
\hline 5. & $\begin{array}{l}\text { Frekuensi } \\
\text { penggunaan media }\end{array}$ & $\begin{array}{l}10-40 \text { jam per } \\
\text { bulan } \\
>40 \text { jam per bulan }\end{array}$ & $\begin{array}{l}<10 \text { jam per bulan } \\
10-40 \text { jam per bulan } \\
>40 \text { jam per bulan }\end{array}$ \\
\hline 6. & $\begin{array}{l}\text { Pemanfaatan media } \\
\text { sosial }\end{array}$ & $\begin{array}{ll}\text { - } & \text { Bertukar } \\
\text { informasi } \\
\text { - } & \text { Mencari } \\
\text { informasi } \\
\text { - } & \text { Memberikan } \\
& \text { informasi baru } \\
- & \text { Melakukan } \\
& \text { penyuluhan dan } \\
& \text { atau sosialisasi } \\
- & \text { Hiburan }\end{array}$ & $\begin{array}{ll}\text { - } & \text { Bertukar informasi dengan sesama } \\
\text { petani atau dengan kelompok. } \\
\text { - } & \text { Mencari informasi tentang pertanian. } \\
\text { - } & \text { Penjualan / pemasaran produk online. } \\
\text { - } & \text { Saling melihat hasil produksi } \\
\text { pertanian untuk memotivasi petani } \\
\text { anggota untuk semakin } \\
\text { mengembangkan lahan pertanian. } \\
\text { - } \quad \text { Mencari berbagai resep makanan dan } \\
\text { masakan. } \\
\text { - } \quad \text { Hiburan }\end{array}$ \\
\hline
\end{tabular}




\begin{tabular}{|c|c|c|c|}
\hline & \multirow{2}{*}{ Aspek sebaran } & \multicolumn{2}{|r|}{ Keterangan } \\
\hline & & Penyuluh & Petani \\
\hline & $\begin{array}{l}\text { Jenis } \\
\text { pelatihan/sosialisasi } \\
\text { penyuluhan yang } \\
\text { diterima }\end{array}$ & $\begin{array}{ll}\text { a. } & \text { Menjawab dan } \\
\text { memberikan } \\
\text { solusi atas } \\
\text { pertanyaan dan } \\
\text { masalah petani } \\
\text { b. } \\
\text { Memberikan } \\
\text { informasi, } \\
\text { pelathian, dan } \\
\text { sosialisasi terkait } \\
\text { kelompok, bibit, } \\
\text { sistem budidaya, } \\
\text { dan sebagainya. }\end{array}$ & $\begin{array}{l}\text { Mendapatkan informasi, pelatihan, dan } \\
\text { sosialisasi tentang: } \\
\text { - } \quad \text { Budidaya manggis } \\
\text { - } \quad \text { Pemanfaatan lahan pekarangan } \\
\text { - } \quad \text { Pemupukan sayuran } \\
\text { - } \quad \text { Teknis budidaya tanaman modern } \\
\text { - } \quad \text { Adminintrasi kelompok } \\
\text { - } \quad \text { Bibit sayuran } \\
\text { - } \quad \text { Benih unggul }\end{array}$ \\
\hline 8. & $\begin{array}{l}\text { Frekuensi sosialisasi } \\
\text { oleh penyuluh } \\
\text { menggunakan media } \\
\text { sosial }\end{array}$ & $\begin{array}{l}1 \text { kali sebulan dan } \\
\text { setiap kali memulai } \\
\text { musim tanam }\end{array}$ & $\begin{array}{l}1 \text { kali sebulan dan setiap kali memulai } \\
\text { musim tanam }\end{array}$ \\
\hline
\end{tabular}

Sumber: hasil olah data primer (2020)

\subsection{Hambatan Penggunaan Media Sosial dalam Penyuluhan Pertanian}

Pelaku pertanian khususnya petani dan penyuluh di Kecamatan Tiumang Kabupaten Dharmasraya juga merasakan berbagai kendala dalam pelanggunaan media sosial sebagai bagian dari media internet. Sebelum petani familiar dengan teknologi tersebut, cukup sulit untuk memperkenalkan petani terhadap media sosial. Selain karena petani belum mengetahui manfaat dari media internet dan media sosial, kendala berupa keterbatasan ekonomi sehingga sulit untuk memperoleh gawai dan selalu memperbaharui paket data internet menjadi hambatan bagi petani. Hal ini seperti yang diungkapkan oleh salah satu petani yang menjadi sumber data penelitian berikut:

"Kalau dulu kan memng tidak tahu cara pakainya. Biasanya telpon orang pakai hp (handphone, red) biasa saja, pokoknya sudah bisa menghubungi orang jauh saja. Kalau sekarang kan memang perlu, jadi harus punya. Saya kan sudah tua, jadi sering numpang pakai punya anak," (N, 52 tahun).

Pernyataan tersebut sesuai dengan hasil penelitian Elian et al. (2014), Walingkas et al. (2016), dan Syathori (2017) yang menyatakan bahwa umur berperan dalam penggunaan internet termasuk media sosial oleh petani. Petani yang memiliki umur produktif ( $<50$ tahun) berpotensi untuk menjadi lebih kreatif dan produktif, lebih mudah menyerap informasi sehingga denagn cepat menyerap dan mengikuti perkembangan teknologi terbaru yang semakin canggih, seperti halnya hasil temuan Leilani et al. (2015) dan Purwatiningsih et al. (2018). 


\section{Tabel 4 Hambatan penggunaan media sosial dalam aktivitas penyuluhan di Kecamatan Tiumang Kabupaten Dharmasraya}

\begin{tabular}{|c|c|c|}
\hline \multirow{2}{*}{ Aspek hambatan } & \multicolumn{2}{|c|}{ Keterangan } \\
\hline & Penyuluh & Petani \\
\hline $\begin{array}{l}\text { 1. Kendala dalam } \\
\text { penggunaan } \\
\text { media sosial. }\end{array}$ & $\begin{array}{ll}\text { - } & \text { Jaringan yang kurang bagus } \\
\text { terutama di lokasi binaan yang } \\
\text { sudah masuk ke daerah pelosok. } \\
\text { - } \quad \text { Kuota internet smartphone habis } \\
\text { ketika sedang berada di lapangan. }\end{array}$ & $\begin{array}{l}\text { - Jaringan yang kurang } \\
\text { bagus, di mana ketika } \\
\text { listrik padam jaringan } \\
\text { akan ikut hilang. } \\
\text { - Modus penipuan jual beli } \\
\text { produk pertanian berbasis } \\
\text { online. }\end{array}$ \\
\hline $\begin{array}{l}\text { 2. Langkah jika } \\
\text { pesan yang } \\
\text { disampaikan } \\
\text { tidak dipahami } \\
\text { oleh pihak lain. }\end{array}$ & $\begin{array}{ll}\text { - } & \text { Diskusi tatap muka dengan petani } \\
\text { di lokasi binaan. } \\
\text { - } \\
\text { Melakukan aktivitas tanya jawab } \\
\text { perihal yang belum dipahami. } \\
\text { - } & \text { Memberikan materi secara lisan } \\
\text { ketika diskusi tatap muka dengan } \\
\text { kelompok. } \\
\text { - } \\
\text { Memberikan praktik langsung di } \\
\text { lapangan atau lokasi binaan. }\end{array}$ & 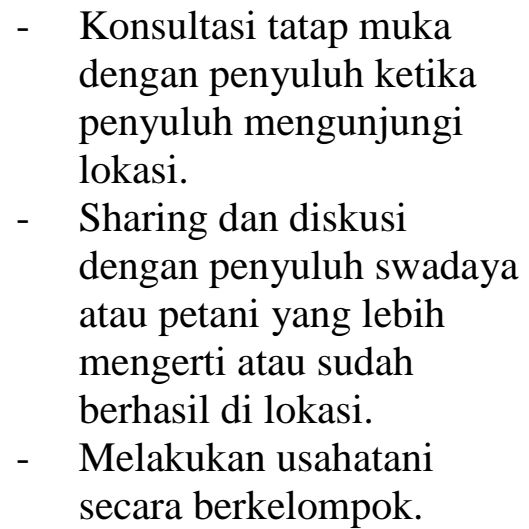 \\
\hline $\begin{array}{l}\text { 3. Upaya yang } \\
\text { dilakukan agar } \\
\text { petani mau } \\
\text { menggunakan } \\
\text { media sosial. }\end{array}$ & $\begin{array}{l}\text { Melakukan aktivitas penyuluhan } \\
\text { dan sosialisasi mengenai manfaat } \\
\text { dan pentingnya penggunaan media } \\
\text { sosial dan media internet untuk } \\
\text { meningkatkan kualitas dan } \\
\text { keuntungan dalam berusahatani. }\end{array}$ & $\begin{array}{l}\text { - Memberitahu anggota atas } \\
\text { manfaat internet dan } \\
\text { media sosial dalam } \\
\text { mengembangkan } \\
\text { usahatani. }\end{array}$ \\
\hline
\end{tabular}

\section{Sumber: hasil olah data primer (2020)}

Charina et al. (2016) dalam hasil penelitiannya mengenai penerapan teknologi informasi dan komunikasi pada kelompok tani menyebutkan bahwa terdapat dua jenis hambatan penerapan TIK termasuk penggunaan media sosial, yaitu hambatan internal dan hambatan eksternal. Hambatan internal merupakan hambatan yang berasal dari dalam diri individu itu sendiri, seperti kurangnya keterampilan dan motivasi penyuluh atau petani dalam menggunakan media sosial. Kondisi di lokasi penelitian menunjukkan bahwa meskipun awalnya tidak banyak petani menggunakan media sosial, sejak tahun 2018 lambat laun petani di Kecamatan Tiumang Kabupaten Dharmasraya mulai menggunakan media sosial. Hal ini disebabkan terutama karena penyuluh melalui BPP menggalakkan program penyuluhan berbasis media sosial. 


\subsection{Dampak Penggunaan Media Sosial dalam Penyuluhan Pertanian}

Tabel 5 Dampak penggunaan media sosial dalam aktivitas penyuluhan di Kecamatan Tiumang Kabupaten Dharmasraya

\begin{tabular}{|c|c|c|}
\hline \multirow{2}{*}{ Pelaku } & \multicolumn{2}{|c|}{ Dampak penggunaan } \\
\hline & Sebelum & Sesudah \\
\hline 1. Penyuluh & $\begin{array}{l}\text { - Aktivitas penyuluhan dilakukan } \\
\text { secara konvensional (tatap } \\
\text { muka) dengan mendatangi } \\
\text { rumah petani atau kediaman } \\
\text { kelompok. } \\
\text { - } \quad \text { Diskusi, tanya jawab, dan } \\
\text { koordinasi jarak jauh dilakukan } \\
\text { menelepon petani secara pribadi. } \\
\text { - } \text { Informasi yang diperoleh oleh } \\
\text { salah satu petani akan } \\
\text { disampaikan kepada anggota } \\
\text { lain dari mulut ke mulut. } \\
\text { Materi penyuluhan dan } \\
\text { sosialisasi terbaru tidak dapat } \\
\text { langsung diberikan, harus } \\
\text { menunggu pertemuan } \\
\text { selanjutnya. } \\
\text { Pengetahuan petani tentang } \\
\text { program umumnya tidak lebih } \\
\text { baik dari penyuluh }\end{array}$ & 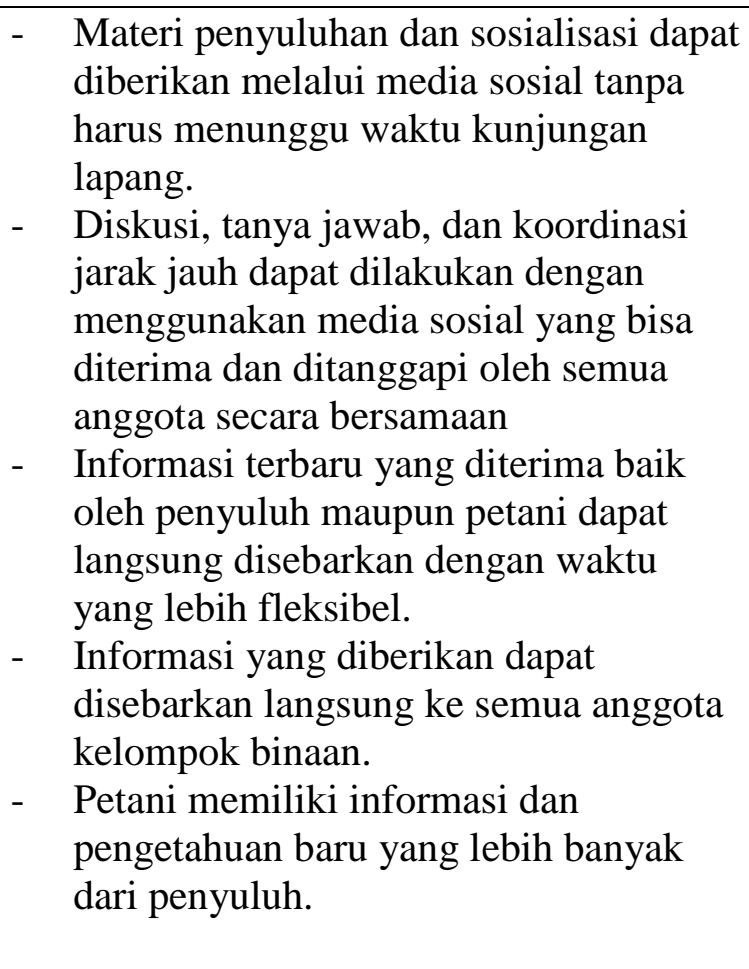 \\
\hline 2. Petani & $\begin{array}{l}\text { Waktu untuk diskusi dengan } \\
\text { penyuluh PNS dan penyuluh } \\
\text { swadaya terbatas hanya pada } \\
\text { saat pertemuan. } \\
\text { Tidak memiliki jaringan pasar } \\
\text { yang luas dan beragam untuk } \\
\text { memasarkan hasil pertanian, } \\
\text { sehingga hanya tergantung } \\
\text { kepada tengkulak. } \\
\text { - Tidak memiliki sumber } \\
\text { informasi yang beragam dan } \\
\text { mudah diakses. } \\
\text { Tidak memiliki media untuk } \\
\text { dapat berdiskusi dengan sesama } \\
\text { petani baik di dalam kelompok } \\
\text { maupun luar kelompok dengan } \\
\text { waktu dan tempat yang } \\
\text { fleksibel. }\end{array}$ & $\begin{array}{l}\text { Memiliki waktu diskusi yang lebih } \\
\text { banyak dan fleksibel dengan penyuluh, } \\
\text { tidak terbatas hanya ketika temu } \\
\text { lapang. } \\
\text { - Memiliki jaringan pasar yang luas dan } \\
\text { beragam untuk memasarkan hasil } \\
\text { pertanian melalui berbagai aplikasi } \\
\text { media sosial. } \\
\text { Dapat dengan mudah mengakses } \\
\text { berbagai informasi pertanian kapanpun } \\
\text { dan di manapun, baik berupa artikel, } \\
\text { audio, visual, maupun audiovisual } \\
\text { berupa video. } \\
\text { Memiliki media diskusi yang dapat } \\
\text { diakses secara pribadi maupun grup } \\
\text { diskusi dengan waktu dan tempat yang } \\
\text { lebih fleksibel. }\end{array}$ \\
\hline
\end{tabular}

Sumber: hasil olah data primer (2020) 


\section{KESIMPULAN}

Penggunaan media sosial dalam kegiatan penyuluhan dilakukan untuk menyebarkan materi penyuluhan, pelatihan, dan sosialisasi; mencari dan memberikan informasi pertanian; media berdiskusi dan pembelajaran; aktivitas penjualan/pemasaran hasil pertanian; dan sebagai media untuk hiburan. Hambatan penggunaan media sosial dalam kegiatan penyuluhan pertanian di Kecamatan Tiumang Kabupaten Dharmasraya umumnya merupakan hambatan eksternal atau terkait fasilitas, yaitu jaringan yang kurang bagus terutama di lokasi binaan yang sudah masuk ke daerah pelosok, hilangnya jaringan internet ketika listrik padam dan cuaca buruk, serta kuota internet smartphone habis ketika sedang berada di lapangan. Dampak penggunaan media sosial dalam kegiatan penyuluhan pertanian di Kecamatan Tiumang Kabupaten Dharmasraya adalah peningkatan akurasi, efektifitas, dan efisiensi dalam penyampaian informasi oleh para pelaku penyuluhan pertanian (penyuluh dan petani); meningkatnya intensitas kegiatan pembelajaran dan percontohan di forum diskusi pada media sosial; dan peningkatan produktivitas usahatani petani yang berdampak pada peningkatan pendapatan hingga peningkatan kesejahteraan petani.

\section{SARAN}

Bagi lembaga pemerintah yang berwenang dalam peningkatan kapasitas dan kapabilitas penyuluh di Kecamatan Tiumang Kabupaten Dharmasraya agar memberikan pelatihan dan pengembangan komptensi penyuluh terutama terkait penggunaan teknologi informasi, serta keahlian untuk mengolah kembali informasi yang telah didapatkan agar dapat disebarkan kepada petani dengan lebih akurat.

\section{DAFTAR PUSTAKA}

[1] Achmad. 2007. Membangun SDM Pertanian yang Profesional TOT TBL Penyuluh Bogor.

[2] Ahuja, V. 2011. Cyber Extension: A Convergence of Ict and Agricultural Development. Global Media Journal-Indian Edition. 2 (2), 1-8.

[3] Bothma, T., Cosijn, E., Fourie, I., dan Penzhorn, C. 2009. Navigating Information Literacy : Your Information Society Survival Toolkit. Cape Town: Pearson Education South Africa.

[4]Manulang, M. 1981. Manajemen Personalia, Jakarta Edisi I, Penerbit Ghalia Indonesia.

[5] Humaidi, L., Hubeis, A.V.S., Puspitawati, H., Anwas, O.E.M. 2020. Karakteristik Penyuluh dalam Pemanfaatan Media Sosialsebagai Media Informasi Pertanian. Agrisocionomics, Jurnal Sosial Ekonomi dan Kebijakan Pertanian: 4(1): 111-124. 